health; and of those mentioned by Professor Rolleston, all have been free from fever epidemics for five or six years, except Rawulpindi. The dry-earth system has been carried out in great perfection for the last six years in the Lahore Central Gaol, which has a population of 2000 convicts, and for upwards of four years the institution has been singularly healthy. The Amballa gaol, too, where one of the most terrible epidemics on record occurred, has been exceedingly healthy for several years, and there, as in the other gaols, the dry-earth system has been in full operation. There has been a marked improvement in the health of the convict population during the last five years. I do not attribute the improvement wholly or even chiefly to the dry-earth system. In my opinion the measure which, beyond all others, has lessened the mortality in Punjab gaols is the care now taken to prevent the introduction of contagious diseases, and to isolate them whenever they evade the checks on their admission; but I feel no doubt whatever that the dry-earth system has been an unmixed good, and that a considerable share of the improvement of the health of the gaol population is to be credited to its adoption. I feel it the more incumbent upon me to acknowledge the benefits which the dry-earth system has conferred on Punjab gaols, as I have in my official reports strongly maintained that that system is altogether unsuited to towns, an opinion to which I still adhere.

I am, Sir, your obedient servant,

A. C. C. DE ReNzY,

Kingstown, Feb. 2nd, 1871. Sanitary Commissioner, Panjab.

\section{THE TURKISH BATH IN THE TREATMENT OF THE INSANE.}

To the Editor of THE LANCET.

SIR,-An extravagant statement made at the North Wales Asylum in reference to the power of the Turkish bath in the treatment of insanity, has given you occasion to express your doubts of its value, and abuse medical superintendents generally. We can afford to bear, and smile at the abuse. We may not be doing much for what you and others call science, but we may still be labouring hard, and not unsuccessfully, to bring about the cure and well-being of our patients.

Now, as one who has had a Turkish bath in full operation for six years, and treated hundreds of patients by it annually, I claim to say a few words upon this subject. The third and last edition of a little work on the bath, publisbed for me by Mr. Hardwicke, is out of print, or I would have sent you a copy. In addition to this, I have published some cases illustrative of the value of bathing, in the Journal of Mental Science.

There can be little doubt that the extraordinary statement made at the North Wales Asylum, as to the percentage of cases cured by the agency of the Turkish bath, is in error. It is probable that the truth of the matter is that 74 per cent. of "recovered" cases had been treated by the Turlzish bath with markedly good effect, rather than that 74 per cent. of insane cases had been absolutely cured by it. The great majority of "recovered" cases here are treated by this therapentic agent, but $\Upsilon$ am not in a position to state positively that they are cured by it. How should I be? Of one thing, however, I am quite certain; and that is that the duration of disease is much shortened by it, and that whenever the period of convalescence commences, perfect health is rapidly attained. It is remarkable how assured of this fact are the patients themselves, and how they give expression, on leaving the asylum, to the high estimate which they have formed of the 'I'urkish bath in their own individual cases. Even those who most set themselves against its use are soon brought to see and feel its efficacy. The argument which they make use of at first is that they are already very weak, and have no desire to be made weaker by sweating. But I put them in the scales and give them ocular demonstration of the flesh which they are making nnder a process which they had previously regarded as debilitating. Somehow or other there seems to be eliminated from the system something which interfered with the process of nutrition, and so a man under this free sudorification will gain a stone or more in a few weeks. The skin, previously coated with epithelium, having a most unpleasant odour, and giving that peculiar dryness and roughness so characteristic of insanity, becomes soft and smooth, presenting a breathing surface, by which no doubt some oxygen is taken into the system, and the powex of excretion greatly augmented.

The cases to which the 'Turkish bath is most adapted are those of melancholia and acute dementia. I have under treatment at this time a case of determined suicidal melancholia in a man of low type and organisation, cursed, too, with an hereditary predisposition to insanity. 'Twice he has attempted suicide since his adnission bere three months ago. A fortnight since I gave him his first Turkish bath, and he has wonderfully improved under its repetition every third day. He is now lively and cheerful, talks of the prospect of returning home, and is no longer (as before) under special charge.

Cases of acute mania are not amenable to the treatment by the Turkish bath. The excitement sometimes becomes so. great in the hot chamber, the skin getting no relief by sweating, that $I$ have quite given up subjecting those labouring under this disease to a process which might involve the risk of a serious casualty. A struggle with a violent patient in a Turkish bath would be a very grave matter, which the generous public, and the yet more generous. press, would not fail to turn to pretty good account against the medical superintendents of asylums. The wet sheet is the great remedy for acute mania, with a burning skin and great excitement. But as soon as ever the acute stage has subsided, the calidarium comes in as a very powerful and valuable agent.

Whether these facts are sufficiently "scientific" for THE LANCET, in its high estimate of the work done by London hospital physicians, as against those who have charge of our county lunatic asylums, $I$ do not pretend to determine. To me, and to those about me, they are potential realities, which evidence the mitigation of suffering, and the more speedy and assured removal of disease.

I am, Sir, your obedient servant,

Middlesex County Lunatic Asylum, Med. Sup. of Male Department Colney Hatch, Feb. 14th, 1871.

** Dr. Sheppard is mistaken in supposing that we expressed doubts of the value of the Turkish bath in the treatment of insanity. We expressed doubts of the scientific value of the information hitherto given regarding its use. We do not think that Dr. Sheppard's opinion of its alleged effects in making the skin smooth and soft, "presenting a breathing surface, by which no doubt some oxygen is taken into the system, and the power of excretion greatly augmented," is quite of that precise scientific character which we wished for. Medical superintendents must not be too sensitive. They, like other people, will be justified, not by the faith they claim, but by the work they do.-ED. L.

\section{CAN THE DEAD CONVEY INFECTION?}

\section{To the Editor of THE LANCET.}

SIR,- - This question has been raised in your columns by Dr. Wilks. After observing that there is every reason to believe "that there is no poisonous gaseous emanation arising from the bodies of those who have died of specific contagious fevers, which is capable of engendering the disease in others," he remarks that possibly "the blood of scarlet fever, small-pox, or syphilis, which is said to contain the specific germs of these diseases during the lifetime of the patient, may retain its reproductive power some hours after death." Permit me to communicate the following fact, which bears strongly on the possibility above alluded to.

Early in last year I had, along with Mr. Wintle, of Kensington, and in the absence of my colleague Dr. Dickinson, who had previously been in attendance, to take charge of one of the students of St. George's Hospital, who contracted scarlet fever (which was accompanied by very alarming symptoms, butwhich, happily, was entirely recovered from) under the following cir. cumstances:-A man, aged twenty-six, was taken ill on 